\title{
PENGARUH EARNING PER SHARE (EPS), DEBT TO EQUITY RATIO, (DER), DAN RETURN ON ASSETS (ROA) TERHADAP RETURN SAHAM PADA PERUSAHAAN MANUFAKTUR YANG TERDAFTAR DI BEI
}

\author{
*(Ratna Handayati ${ }^{1}$, Noer Rafikah Zulyanti ${ }^{2}$ \\ Prodi Manajemen, Fakultas Ekonomi, Universitas Islam Lamongan \\ $\mathrm{Jl}$. Veteran No.53A Lamongan \\ Telp. ( 0322 ) 324706, Faks. ( 0322 ) 324706 \\ Email :jpim.unisla@gmail.com
}

\begin{abstract}
ABSTAKSI
Penelitian Pengaruh EPS, DER, dan ROA terhadap return saham pada perusahan maufaktur yang terdaftar di BEI bertujuan untuk menganalisis pengaruh Earning Per Share (EPS), Debt to Equity Ratio (DER), dan Return On Assets (ROA) terhadap return saham pada perusahan maufaktur yang terdaftar di BEI. Metode penelitian yang digunakan adalah metode kuantitatif dengan perhitungan Regresi menggunakan software SPSS versi 16.0 Hasil penelitian mengungkapkan bahwa Earning Per Share $\left(X_{1}\right)$ Debt to Equity Ratio $\left(X_{2}\right)$, Return On Assets $\left(X_{3}\right)$ dan jumlah tenaga kerja $\left(X_{4}\right)$ mempunyai pengaruh signifikan terhadap return saham
\end{abstract}

Kata Kunci: Earning Per Share (EPS), Debt to Equity Ratio (DER), Return On Assets (ROA), Return saham

\section{PENDAHULUAN}

Dengan berkembangnya pasar modal yang cukup pesat membuat para investor banyak melakukan kegiatan berinvestasi untuk mendapatkan return, demikian para borrower dengan mudah mendapatkan dana dari investor untuk mengembangkan perusahaan yang dimilikinya. Para investor dalam menginvestasikan dananya memiliki tujuan untuk meningkatkan return di masa mendatang yaitu mendapatkan return sebesar-besarnya dari hasil deviden yang dimilikinya maupun dari capital gain yang besar.

Para investor menanamkan modalnya kepada borrower, pihak borrower adalah pihak yang memerlukan dana yang digunakan untuk mengembangkan dananya, tentu dengan melihat bagaimana kualitas perusahaan itu dalam mengembangkan perusahaannya.
Perusahaan bisa mendapatkan return yang menguntungkan pihak investor dengan melihat return dari keuntungan portofolio yang didapat perusahaan dari capital gain maupun dari deviden perusahaan. Pihak investor sangatlah berhati-hati dalam pemilihan perusahaan yang akan menjadi tempat untuk berinvestasi agar mendapaykan return dan tidak terjadi kerugian yang mengakibatkan dana yang ditanamkan investor tidak mendapatkan return dari perusahaan tersebut.

Return saham adalah keuntungan yang diperoleh oleh perusahaan, individu, dan institusi dari hasil kebijakan investasi yang dilakukannya. Dalam dunia investasi dikenal adanya hubungan kuat antara risk dan return, yaitu jika resiko tinggi maka return (keuntungan) juga akan tinggi begitu juga sebaliknya jika return rendah maka resiko juga akan rendah (Fahmi, 2014:450). 
Berdasarkan latar belakang di atas maka penulis tertarik untuk melakukan penelitian tentang "Pengaruh EPS, DER, dan ROA terhadap return saham pada perusahan maufaktur yang terdaftar di BEI". Penelitian ini bertujuan untuk menganalisis pengaruh Earning Per Share (EPS), Debt to Equity Ratio (DER), dan Return On Assets (ROA) secara simultan terhadap return saham dan untuk menganalisis pengaruh Earning Per Share (EPS), Debt to Equity Ratio (DER), dan Return On Assets (ROA) secara parsial terhadap return saham pada perusahan maufaktur yang terdaftar di BEI.

\section{TINJAUAN PUSTAKA}

Pengertian Pasar Modal

Pasar modal (Capital Market) adalah pasar yang menjadi penghubung antara pemilik dana (investor) dengan pengguna dana (emiten). Pemilik dana (investor) adalah mereka, baik individu maupun lembaga atau badan usaha yang menyisihkan kelebihan dana yang dimilikinya untuk diinvestasikan agar lebih produktif (Situmorang, 2008:1). Pasar modal merupakan instrumen ekonomi yang sangat penting karena pasar modal menyediakan fasilitas untuk memindahkan dana dari pihak yang memiliki kelebihan dana (lenders) kepada pihak yang membutuhkan dana (borrower). Dengan menginvestasikan kelebihan dana yang dimilikinya, lenders (investor) akan memperoleh return dari penyerahan dana tersebut sedangkan borrower akan menggunakan dana tersebut untuk kepentingan investasi tanpa harus menunggu tersedianya dana dari kegiatan usaha perusahaan (Situmorang, 2008:4).

\section{Return Saham}

Return saham adalah keuntungan yang diperoleh oleh perusahaan, individu, dan institusi dari hasil kebijakan investasi yang dilakukannya. Dalam dunia investasi dikenal adanya hubungan kuat antara risk dan return, yaitu jika resiko tinggi maka return (keuntungan) juga akan tinggi begitu juga sebaliknya jika return rendah maka resiko juga akan rendah (Fahmi, 2014:450).

Menurut Jogiyanto (2010:205) return merupakan hasil yang diperoleh dari investasi. Return dapat berupa return realisasi yang sudah terjadi atau return ekspektasi yang belum terjadi tetapi yang diharapakan akan terjadi dimasa mendatang. Return realisasi (realizad return) dihitung menggunakan data historis. Return realisasi sangat penting karena digunakan sebagai salah satu pengukur kinerja dari perusahaan dan dasar penentuan return ekpektasi. Return ekspetasi (expected return) adalah return yang diharapkan akan diperoleh investor dimasa mendatang.

\section{Faktor-Faktor yang Mempengaruhi Return Saham}

Ada beberapa faktor yang mempengaruhi return saham, diantaranya Earning Per Share (EPS), Debt to Equity Ratio (DER), dan Return On Assets (ROA). Menurut Darmadji dan Fakhruddin (2006), Earning Per Share (EPS) merupakan salah satu rasio pasar yang dapat di gunakan untuk mengetahui hasil dari perbandingan antara pendapatan yang akan diterima oleh pemegang saham atau para investor dan pendapatan yang dihasilkan (laba bersih) terhadap harga saham setiap lembarnya dalam perusahaan.

Menurut Darmadji dan Fakhruddin (2006) Debt to Equity Ratio (DER) 
menggambarkan kemampuan perusahaan dalam memenuhi segala kewajibannya yang ditunjukkan oleh beberapa bagian dari modal sendiri atau ekuitas yang digunakan untuk membayar hutang. Debt to Equity Ratio (DER) merupakan perbandingan antara total hutang yang dimiliki perusahaan dengan totalekuitasnya.

Return On Asset (ROA) yaitu rasio antara Net Income After Tax terhadap aset secara keseluruhan menunjukan ukuran produktivitas aktiva dalam memberikan pengembalian pada penanaman modal (Sawir,2001). Return On Asset (ROA) digunakan untuk mengukur efiktivitas perusahaan di dalam menghasilkan keuntungan dengan memanfaatkan aktiva yang dimilikinya. Menurut Henry (2006:529) Return on Asset yaitu, Rasio imbalan aktiva (ROA) merupakan suatu ukuran keseluruhan profitabilitas perusahaan.

\section{Hipotesis}

Menurut Narimawati (2010) hipotesis merupakan asumsi atau dugaan sementara yang harus di uji kebenarannya dalam suatu analisis statistik. Berdasarkan landasan teori di atas, maka diperoleh hipotesis sebagai berikut:

$\mathrm{H}_{1}$ : Earning Per Share (EPS), Debt to Equity Ratio (DER), dan Return On Assets (ROA) berpengaruh secara simultan terhadap return saham pada perusahan maufaktur yang terdaftar di BEI.

$\mathrm{H}_{2}$ : Earning Per Share (EPS), Debt to Equity Ratio (DER), dan Return On Assets (ROA) berpengaruh secara parsial terhadap return saham pada perusahan maufaktur yang terdaftar di BEI.

\section{METODE PENELITIAN}

Penelitian ini merupakan penelitian kuantitatif. Data yang diambil adalah data sekunder yang telah diolah oleh pihak perusahaan dan sudah diterbitkan dalam bentuk laporan keuangan atau dengan kata lain data tersebut tidak terdapat pada perusahaan yang bersangkutan. Data tersebut diperoleh dari Summary of Financial Statement yang tercantum dalam Indonesia Capital Market Directory (ICMD) dan berbagai sumber data website www.idx.ci.id

Populasi dalam penelitian ini adalah perusahaan manufaktur dalam bidang makanan dan minuman yang terdaftar di Bursa Efek Indonesia pada periode 2014-2016. Pengambilan sampel dilakukan dengan metode Purposie Sampling dengan kriteria sabagai berikut : (1) Perusahaan manufaktur dalam bidang makanan dan minuman yang terdaftar di Bursa Efek Indonesia pada periode 2014-2016. (2) Perusahaan manufaktur dalam bidang makanan dan minuman yang membayarkan return saham pada periode 2014-2016. (3) Perusahaan manufaktur dalam bidang makanan dan minuman yang menerbitkan laporan keuangan lengkap yang meliputi EPS, DER, dan ROA selama periode penelitian.

Dalam penelitian ini terdiri dari tiga variabel bebas (X) dan satu variabel terikat (Y) yaitu Earning Per Share $\left(\mathrm{X}_{1}\right)$, Debt to Equity Ratio $\left(\mathrm{X}_{2}\right)$, Return On Asset $\left(\mathrm{X}_{3}\right)$ dan Return Saham (Y). Untuk mencari pengaruh Earning Per Share (EPS), Debt to Equity Ratio (DER), dan Return On Assets (ROA) terhadap return saham, maka dalam penelitian ini menggunakan beberapa alat uji statistik, 
yaitu regresi linier berganda, uji t, dan uji F.

\section{HASIL DAN PEMBAHASAN}

HASIL

\section{Analisis Regresi Linear Berganda}

Dengan menggunakan analisis linear berganda dapat diketahui pengaruh variabel bebas terhadap variabel terikat. Berikut ini adalah ringkasan analisis linear berganda :

Tabel 1

Regresi Linear Berganda

\begin{tabular}{|l|l|}
\hline Variabel bebas & $\begin{array}{l}\text { Keterangan } \\
\text { regresi }\end{array}$ \\
\hline Konstanta & 107,323 \\
\hline EPS $\left(\mathrm{X}_{1}\right)$ & $-0,400$ \\
\hline DER $\left(\mathrm{X}_{2}\right)$ & 218,966 \\
\hline ROA $\left(\mathrm{X}_{3}\right)$ & $-3,300$ \\
\hline
\end{tabular}

Berdasarkan Tabel 1 di atas, maka persamaan regresi return saham perusahaan manufaktur dalam bidang makanan dan minuman adalah sebagai berikut:

$Y=107,323-0,400 X_{1}+218,966 X_{2}$ $-3,300 X_{3}$

Hasil dari persamaan regresi linear berganda tersebut memberikan pengertian :

Untuk koefisien regresi EPS $\left(X_{1}\right)$ sebesar $-0,400$. dimana tanda negatif dalam persamaan linear tersebut menunjukkn pengaruhnya adalah negatif, yang artinya apabila EPS mengalamin kenaikan, maka return saham akan turun sebesar $40 \%$ apabila variabel bebas lainnya konstan.

Untuk koefisien regresi DER $\left(\mathrm{X}_{2}\right)$ sebesar 218,966. dimana tanda positif dalam persamaan linear tersebut menunjukkn pengaruhnya adalah positif, yang artinya apabila DER mengalamin kenaikan, maka return saham akan naik sebesar $12,751 \%$ apabila variabel bebas lainnya konstan.

Untuk koefisien regresi ROA $\left(X_{3}\right)$ sebesar 3,300. dimana tanda negatif dalam persamaan linear tersebut menunjukkn pengaruhnya adalah negaif, yang artinya apabila ROA mengalamin kenaikan, maka return saham akan turun sebesar $3,30 \%$ apabila variabel bebas lainnya konstan.

2. Uji hipotesis ( uji t )

Untuk menganalisa pengaruh variabel Earning Per Share $\left(\mathrm{X}_{1}\right)$, Debt to Equity Ratio $\left(\mathrm{X}_{2}\right)$, Return On Asset $\left(\mathrm{X}_{3}\right)$ secara parsial terhadap variabel Return Saham (Y), maka akan dirangkum dalam tabel berikut :

Tabel 2

Rangkuman Hasil Perhitungan uji hipotesis

\begin{tabular}{|l|l|l|}
\hline Model & t- hitung & Sig \\
\hline (Constant) & 1,022 & 0,313 \\
\hline EPS & $-3,111$ & 0,003 \\
\hline DER & 3,549 & 0,001 \\
\hline ROA & 2,902 & 0,004 \\
\cline { 1 - 1 } F =6,233 & \\
\cline { 1 - 1 } Sig =0,001 & \\
\cline { 1 - 1 } R Square = \\
0,384 \\
\cline { 1 - 1 } R Adjusted \\
Square = \\
0,322
\end{tabular}

Dari tabel 2 dapat diketahui bahwa $\mathrm{t}$ hitung untuk variabel Earning Per Share $\left(\mathrm{X}_{1}\right)$ sebesar -3,111 dengan tingkat signifikan 0,003 . Lebih kecil dari 0,005 yang artinya Earning Per Share berpengaruh signifikan terhadap return saham. Kesimpulannya Ho ditolak dan $\mathrm{H}_{1}$ diterima, hal ini menunjukkan bahwa EPS 
berpengaruh terhadap return saham.

Untuk variabel Debt to Equity Ratio $\left(\mathrm{X}_{2}\right)$, diketahui $\mathrm{t}$ hitung sebesar 3,549 dengan tingkat signifikan 0,001. Lebih kecil dari 0,005 yang artinya Debt to Equity Ratio berpengaruh terhadap return saham. Kesimpulannya Ho ditolak dan $\mathrm{H}_{1}$ diterima, hal ini menunjukkan bahwa DER berpengaruh terhadap return saham.

Dari tabel 2 dapat diketahui bahwa t hitung untuk variabel Return On Asset $\left(\mathrm{X}_{3}\right)$ sebesar 2,902 dengan tingkat signifikan 0,004 . Lebih kecil dari 0,005 yang artinya Return On Asset berpengaruh signifikan terhadap return saham. Kesimpulannya Ho ditolak dan $\mathrm{H}_{1}$ diterima, hal ini menunjukkan bahwa ROA berpengaruh terhadap return saham.

3. Uji F

Berdasarkan tabel 2 angka adjusted R Square adalah 0,384 sebagai dasar menghitung koefisien determinasi. Nilai koefisien determinasi adalah $38,4 \%$ artinya variabel EPS, DER dan ROA berpengaruh simultan terhadap return saham sedangkan sisanya sebesar $61,6 \%$ dipengaruhi oleh variabel lainnya yang tidak dibahas dalam penelitian ini.

Nilai koefisien $F$ sebesar 6,233 dan nilai signifikan 0,001 dimana dapat diartikan bahwa F lebih besar dari 0,05 maka dapat diartikan Ho diterima sehingga variabel EPS, DER dan ROA secara bersama-sama berpengaruh terhadap return saham.

\section{PEMBAHASAN}

1. Pengaruh Earning Per Share (EPS) terhadap return saham

Pada penelitian ini menunjukkan bahwa EPS dalam uji t, Ho ditolak dan $\mathrm{H}_{1}$ diterima, yang artinya bahwa EPS berpengaruh secara parsial terhadap return saham. Diketahui $\mathrm{t}$ hitung untuk variabel Earning Per Share $\left(\mathrm{X}_{1}\right)$ sebesar -3,111 dengan tingkat signifikan 0,003. Lebih kecil dari 0,005 yang artinya Earning Per Share berpengaruh signifikan terhadap return saham.

Earning Per Share merupakan rasio pasar yang pada dasarnya mengukur kemampan manajemen dalam menciptakan nilai pasar yang melampaui pengeluaran investasi. Kenaikan EPS berarti perusahaan sedang dalam pertumbuhan, kondisi keuangan yang meningkat baik dalam peningkatan penjualan maupun laba, semakin besar EPS menunjukkan kemampuan perusahaan menghasilkan keuntungan bersih setiap lembarnya.

2. Pengaruh Debt to Equity Ratio (DER) terhadap return saham

Untuk variabel Debt to Equity Ratio $\left(\mathrm{X}_{2}\right)$ dalam uji t, Ho ditolak dan $\mathrm{H}_{1}$ diterima yang artinya bahwa DER berpengaruh secara parsial terhadap return saham.. Diketahui t hitung sebesar 3,549 dengan tingkat signifikan 0,001. Lebih kecil dari 0,005 yang artinya Debt to Equity Ratio berpengaruh signifikan terhadap return saham.

DER merupakan perbandingan antara seluruh hutang perusahaan baik hutang jangka panjang maupun hutang jangka pendek. Semakin tinggi DER maka akan menunjukkan ketergantungan 
perusahaan terhadap pihak luar (Kreditur)

3. Pengaruh Return On Asset (ROA) terhadap return saham

Pada penelitian ini menunjukkan bahwa ROA dalam uji t, Ho ditolak dan $\mathrm{H}_{1}$ diterima, yang artinya bahwa ROA berpengaruh secara parsial terhadap return saham. Diketahui $\mathrm{t}$ hitung untuk variabel Return On Asset $\left(\mathrm{X}_{3}\right)$ sebesar 2,902 dengan tingkat signifikan 0,004. Lebih kecil dari 0,005 yang artinya Return On Asset berpengaruh signifikan terhadap return saham.

Semakin tinggi nilai ROA maka kinerja perusahaan dianggap semakin baik dan demikian pula sebaliknya. Meningkatnya ROA berarti perusahaan dianggap mampu menghasilkan laba perusahaan yang tinggi dan sebagai dampaknya harga saham perusahaan meningkat. Terjadinya peningkatan harga saham berakibat pula pada peningkatan return saham perusahaan yang diterima pemegang saham.

\section{KESIMPULAN}

Berdasarkan hasil analisis dan pembahasan yang telah dikemukakan di atas, maka dapat disimpulkan sebagai berikut :
1. Hasil dari uji $F$ menunjukkan bahwa koefisien $\mathrm{F}$ adalah sebesar 6,233 dan nilai signifikan 0,001 dimana dapat diartikan bahwa $\mathrm{F}$ lebih besar dari 0,05 maka dapat diartikan Ho diterima. Hal ini menunjukkan bahwa Earning Per Share, Debt to Equity Ratio dan Return On Asset secara bersama-sama mempengaruhi variabel Return Saham.

2. Hasil dari uji $\mathrm{t}$ menunjukkan pengaruh variabel independen terhadap variabel dependen secara parsial adalah : Earning Per Share berpengaruh secara parsial terhadap Return Saham, Debt to Equity Ratio berpengaruh secara parsial terhadap Return Saham, Return On Asset berpengaruh secara parsial terhadap Return Saham.

\section{DAFTAR PUSTAKA}

Darmaji, Tjiptono dan Henry $\mathbf{M}$ Fakhrudin. 2006. Pasar Modal di Indonesia: Pendekatan Tanya Jawab. Jakarta: Salemba Empat.

Fahmi, I. 2014. Manajemen Keuangan Perusahaan Dan Pasar Modal. Edisi Pertama. Jakarta: Mitra Wacana Media. Jakarta.

Jogiyanto, H. 2010. Teori Portofolio dan Analisis Investasi. Edisi ketujuh. Cetakan Pertama. Yogyakarta: BPFE.

Situmorang, Paulus, 2008, Pengantar Pasar Modal, Edisi Pertama, Jakarta: Mitra Wacana Media. 